\title{
Suporte Tecnológico para o Auxílio do Professor na Avaliação segundo à BNCC
}

\author{
Letícia M. Portela ${ }^{1}$, Greicy Nayara P. Zagui ${ }^{1}$, Fabio André G. dos Santos ${ }^{2}$, Flávia Aparecida \\ Reitz Cardoso ${ }^{1}$, Rafael Liberato ${ }^{1}$
}

leticiaportela@alunos.utfpr.edu.br, greicypazini@gmail.com, fabio.santos@ifpr.edu.br, reitz@utfpr.edu.br, liberato@utfpr.edu.br

\begin{abstract}
${ }^{1}$ Universidade Tecnológica Federal do Paraná, Via Rosalina Maria dos Santos, 1233, 87301-899, Campo Mourão - PR, Brasil

2 Instituto Federal do Paraná, Rua José Felipe Tequinha, 1400, 87703-536, Paranavaí - PR, Brasil
\end{abstract}

DOI: 10.17013/risti.35.101-116

\begin{abstract}
Resumo: A educação brasileira tem passado por profundas reformulações com a criação da Base Nacional Comum Curricular(BNCC), um documento quetem o intuito de definir um conjunto de aprendizagens essenciais, composto por competências e habilidades que deve ser desenvolvido pelos alunos em cada período da educação básica. A implantação da BNCC afeta diretamente o trabalho do professor, pois ela é responsável por nortear quais habilidades devem ser desenvolvidas pelos alunos e a avaliação caracteriza-se como um dos principais instrumentos utilizados para verificação do progresso do aprendizado. No entanto, fatores como a alta carga horária em sala de aula e o elevado número de alunos sob sua tutela, colocam em risco a eficácia desse instrumento. Assim, objetivou-se a investigação do impacto que uma ferramenta tecnológica pode proporcionar aos professores na elaboração e interpretação dos resultados da avaliação. Para sustentar a investigação, um protótipo foi desenvolvido e aplicado em uma turma do Ensino Fundamental I de uma escola do setor privado. Os resultados mostraram que a ferramenta foi capaz de revelar informações relevantes não percebidas pelo professor.
\end{abstract}

Palavras-chave: Avaliação; Habilidade; Competência; BNCC.

\section{Technology Support for Teacher Assistance in BNCC Assessment}

Abstract: Brazilian education has undergone deep reformulations with the creation of the Common National Curriculum Base (BNCC), a document that aims to define a set of essential learning, composed by competences and and skills to be developed by students in each period of basic education. The BNCC affects the teacher's work, because it is responsible for guiding which skills should be developed by the students and the assessment is characterized as one of the main tools used to verify the learning progress. However, factors such as the high workload in the classroom and the large number of students under its supervision put the effectiveness of this instrument at risk. Thus, the objective was to investigate the impact that a technological tool can provide to teachers on the elaboration and interpretation 
of assessment results. To support the research, a prototype was developed and applied in an elementary school class at a private school. The results showed that the prototype was able to reveal relevant information unnoticed by the teacher.

Keywords: Evaluation; Assessment, Skills; Competence; BNCC.

\section{Introdução}

A educação brasileira tem passado por profundas reformulações com a criação da Base Nacional Comum Curricular (BNCC). Em discussão desde 2015 e com versão final lançada em 2018, a BNCC prevê uma série de modificações para as três etapas da Educação Básica no Brasil: Educação Infantil, Ensino Fundamental e Ensino Médio. A base se caracteriza como um documento governamental normativo criado com o intuito de definir um conjunto de aprendizagens essenciais, compostas por competências e habilidades, que deve ser desenvolvido pelos alunos ao longo do período que contempla a educação básica (Ministério da Educação, 2018). O documento fornece ainda parâmetros para orientar não apenas a elaboração dos currículos, mas também a elaboração e revisão das propostas pedagógicas, as políticas para formação de professores, os materiais didáticos e as avaliações oriundas de escolas públicas e particulares. As escolas devem adequar seus currículos até o início do ano letivo de 2020.

A implantação da BNCC afeta diretamente o professor, pois ele deverá ser capaz de diagnosticar o desempenho dos alunos nas habilidades definidas pelo documento. A avaliação é um dos principais instrumentos para verificar o progresso do aprendizado e fornecer informações relevantes para intervenções pedagógicas. A eficácia desse instrumento está diretamente atrelada à capacidade do professor em elaborar a avaliação e interpretar seus resultados. No entanto, considerando o cenário atual da educação brasileira, alguns fatores colocam em risco a eficácia deste instrumento, tais como: a alta carga horária em sala de aula, o elevado número de alunos sob sua tutela e a ausência de suporte tecnológico adequado à avaliação.

Para exemplificar a influência desses fatores na avaliação, considera-se o cenário real de um professor de História que leciona na rede particular de ensino na cidade de Campo Mourão no estado do Paraná. Este professor possui uma jornada semanal de 20 horas. Leciona 2 aulas da disciplina de História para 1 turma do $6^{\circ}$ ano, 2 turmas do $8^{\circ}$ ano e 6 turmas do $9^{\circ}$ ano, totalizando 18 horas semanais em sala de aula e 2 horas semanais para as demais atividades inerentes à profissão (preparação da avaliação, correção, preparação de aulas, etc.). O professor leciona para, aproximadamente, 200 alunos (entre 20 e 25 alunos por turma). Segundo a BNCC, o aluno deve desenvolver 19 habilidades no $6^{\circ}$ ano, 27 habilidades no $8^{\circ}$ ano e 36 habilidades no $9^{\circ}$ ano. Portanto, o professor deverá ser capaz de diagnosticar o desenvolvimento de 82 habilidades para, aproximadamente, 200 alunos.

Diante do exposto, este trabalho propõe a investigação do impacto que uma ferramenta tecnológica pode proporcionar aos professores na elaboração e interpretação dos resultados da avaliação. A hipótese é que essa ferramenta tecnológica produza informações significativas sobre o desempenho dos alunos que não seriam percebidas dado os fatores supracitados. Essas informações poderiam auxiliar o professor na interpretação dos resultados, potencializando a eficácia da avaliação no processo de 
ensino-aprendizagem. A investigação foi conduzida com o objetivo de responder às seguintes Questões de Pesquisa: (QP1) A ferramenta tecnológica evidenciou informações que foram imperceptíveis ao professor na avaliação dos alunos segundo as habilidades propostas na BNCC? (QP2) As informações evidenciadas pela ferramenta tecnológica proporcionaram reflexões sobre possíveis intervenções pedagógicas?

Para responder à $\mathrm{QP} 1$ e $\mathrm{QP} 2$, inicialmente, desenvolveu-se um protótipo de software com funcionalidades em potencial para auxiliar o professor no processo de avaliação das habilidades da BNCC. Em seguida, o protótipo foi aplicado durante a avaliação na disciplina de Matemática de uma turma do $5^{\circ}$ ano do Ensino Fundamental I em uma escola particular do município de Campo Mourão no estado do Paraná. A aplicação do protótipo ocorreu no segundo quadrimestre de 2019 e teve o acompanhamento da professora da disciplina. As questões de pesquisa foram respondidas com base na discussão dos resultados proporcionados pelo protótipo juntamente com a professora da disciplina e a coordenadora pedagógica.

O artigo está organizado da seguinte forma: a Seção 2 apresenta a fundamentação teórica e os trabalhos relacionados, a Seção 3 descreve a metodologia utilizada, a Seção 4 apresenta os resultados e, por fim, a Seção 5 apresenta a conclusão e os trabalhos futuros.

\section{Fundamentação Teórica e Trabalhos Relacionados}

Esta seção tem por objetivo elucidar os conceitos que serviram de base para a elaboração do presente trabalho.

\subsection{Avaliação de Aprendizagem}

De uma forma geral, a avaliação de aprendizagem se caracteriza como um instrumento para verificar o progresso do estudante e a qualidade do conhecimento adquirido, implicando em uma reflexão que leva a tomadas de decisão para aceitar este resultado ou elaborar estratégias para sua melhoria (Luckesi, 2005). De forma complementar, Carneiro et al. (2017) defendem que a avaliação de aprendizagem é um recurso utilizado continuamente em âmbito educacional, sendo um dos seus papéis direcionar a prática pedagógica com base nos objetivos de aprendizagem que foram propostos. Além disso, Torres, et al. (2018) apontam que a avaliação é um processo fundamental da aprendizagem, visto que ela é responsável por fornecer informações cruciais sobre o desenvolvimento de novos conhecimentos pelos alunos. O pensamento de tais autores se assemelha com o que se encontra na Lei de Diretrizes e Bases da Educação Nacional (LDB), que apresenta a avaliação como um processo cumulativo e contínuo, e aponta que os aspectos qualitativos da avaliação devem prevalecer sobre os aspectos quantitativos (Senado Federal, 2018).

Dessa maneira, cabe ao docente e equipe pedagógica definir a forma com que a avaliação de aprendizagem será conduzida em sala de aula, ou seja, quais os elementos que irão compor todo o processo de avaliação (conteúdos, instrumentos de avaliação, etc.). Assim, o processo de avaliação pode assumir diversos formatos e, devido a isso, são encontrados na literatura algumas classificações de avaliações conforme a metodologia empregada ao longo do seu desenvolvimento e, dentre os tipos de avaliação, destacamse a Avaliação Diagnóstica, a Avaliação Formativa e a Avaliação Somativa. 
De acordo com Nascimento (2017, p. 651), a Avaliação Diagnóstica "acontece antes da ação, no intuito de avaliar qual é o desempenho do educando referente ao processo de ensino, para que se possa desenvolver o currículo escolar em função do que foi diagnosticado”. Assim, se a avaliação diagnóstica for bem executada, é possível traçar estratégias que auxiliem no processo de ensino e aprendizagem.

Já a Avaliação Formativa caracteriza-se por ser contínua e realizada ao longo de todo o período letivo, permitindo constatar se os alunos estão desenvolvendo seus conhecimentos conforme o esperado em cada etapa de aprendizagem, antes de prosseguir para as próximas (Freitas, da Costa \& de Miranda, 2014). Por meio deste tipo de avaliação, o professor tem a possibilidade de realizar intervenções pedagógicas, as quais servem de auxílio tanto para o professor, como para os alunos, visto que o professor pode sanar as dificuldades apresentadas pelos alunos e aperfeiçoar seus procedimentos de ensino.

Por fim, a Avaliação Somativa, também chamada de Classificatória, tem por característica principal ser aplicada no final do processo de ensino, com o objetivo de identificar o nível de aproveitamento do estudante e determinar sua aprovação ou não (Nascimento, 2017). Neste tipo de avaliação há a classificação do aluno com base na quantidade de conhecimento que ele reproduz nas provas.

No que diz respeito à forma com que a avaliação de aprendizagem é tratada na educação brasileira, nos últimos anos houveram muitos debates dos quais um deles culminou na criação da BNCC, uma iniciativa do governo brasileiro que tem por finalidade definir quais as competências que devem ser adquiridas pelos alunos na educação básica. A próxima seção esclarece melhor os aspectos relativos à BNCC.

\subsection{Base Nacional Comum Curricular (BNCC)}

A discussão sobre a criação de uma BNCC começou por volta de 2015 e, desde então, foram lançadas algumas versões da base, até chegar na versão atual (lançada em 2018) que se intitula como a versão final. A criação da BNCC foi pautada na ideia da existência de um currículo unificado na educação, o qual poderia ser adotado pelas escolas de forma a promover a equidade educacional e o alinhamento entre elementos fundamentais da educação, tais como o conteúdo ensinado, formação dos professores, materiais didáticos, dentre outros (Heinsfeld \& da Silva, 2018).

O objetivo da BNCC é o de nortear a formulação dos currículos escolares, de forma que seja possível estipular quais as competências e habilidades que devem ser adquiridas e aperfeiçoadas pelos alunos na educação básica. Alguns países já adotam essa abordagem de ensino pautada no desenvolvimento de competências, como é o caso da Espanha, Colômbia, Peru, dentre outros (Duran et. al., 2017).

Os agrupamentos de competências e habilidades apresentados na BNCC não compõem um modelo obrigatório, mas sim, uma forma de explicitar com clareza o que se deseja que os alunos aprendam ao longo da educação básica (Ministério da Educação, 2018). Além disso, a BNCC deve obedecer à LDB, que explicita em seu Artigo $26^{\circ}$ que "os currículos da Educação Infantil, do Ensino Fundamental e do Ensino Médio devem ter base nacional comum, a ser complementada, em cada sistema de ensino e em cada estabelecimento 
escolar, por uma parte diversificada, exigida pelas características regionais e locais da sociedade, da cultura, da economia e dos educandos (Senado Federal, 2018, p. 19)”.

A estrutura da BNCC foi projetada de modo a promover o desenvolvimento de dez competências gerais distribuídas entre as três etapas da educação básica: Educação Infantil, Ensino Fundamental e Ensino Médio. Segundo a BNCC (Ministério da Educação, 2018, p. 8), "uma competência é uma espécie de mobilizador de conhecimento, habilidade, atitudes e valores pessoais que contribuem na resolução de problemas que não estão apenas na esfera educacional, mas também, na esfera cotidiana”.

Como são apresentados alguns termos importantes ao longo do texto da base, vale ressaltar que alguns destes termos devem ser esclarecidos, como o conceito de competência, por exemplo, um destes termos já esclarecido anteriormente, mas, que ao defini-lo, foi apresentado outro termo muito importante: habilidade, que, de acordo com a BNCC trata-se de um conjunto de elementos que "(...) expressam as aprendizagens essenciais que devem ser asseguradas aos alunos nos diferentes contextos escolares" (Ministério da Educação, 2018, p. 29).

As habilidades foram mapeadas para um código alfanumérico, onde cada grupo de dígitos deste código traz consigo um significado (Ministério da Educação, 2018). O código é composto por quatro pares de caracteres, onde o primeiro par possui duas letras que identificam a etapa da educação básica; o segundo par possui dois números que remetem ao ano de ensino; o terceiro par possui duas letras que caracterizam a disciplina e, por último, o quarto par possui dois números que indicam a posição sequencial da habilidade. Para exemplificar, ao analisar o código EFo5MAo1, sabese que se trata da primeira habilidade da disciplina de Matemática do quinto ano do Ensino Fundamental.

Para comprovar a grande quantidade de habilidades existentes, a Tabela 1 apresenta a quantidade de habilidades de Matemática distribuídas pelos duas etapas do Ensino Fundamental.

\begin{tabular}{ll}
\hline Etapa & Quantidade de habilidades \\
\hline Ensino Fundamental I $\left(1^{\circ}\right.$ ao $5^{\circ}$ ano $)$ & 126 \\
\hline Ensino Fundamental II $\left(6^{\circ}\right.$ ao $9^{\circ}$ ano $)$ & 121 \\
\hline Total & 247 \\
\hline
\end{tabular}

Tabela 1 - Distribuição das habilidades de Matemática no Ensino Fundamental

Como pode-se verificar pela Tabela 1, são muitas habilidades em cada etapa, resultando em uma gama de habilidades que devem ser avaliadas pelo professor apenas para uma disciplina do Ensino Fundamental. Vale ressaltar que o processo de avaliação das competências e habilidades pode acabar se tornando um processo complicado e passível de imprecisão, devido a grande quantidade de informação que deve ser analisada (Duran et al., 2017). Além disso, atualmente não existe nenhuma ferramenta amplamente conhecida que auxilie os professores neste processo de verificação do desenvolvimento das habilidades e competências da BNCC pelos alunos. Para explorar melhor esta 
afirmação, na seção seguinte são apresentados alguns trabalhos que se aproximam um pouco da ideia do protótipo apresentado neste trabalho.

\subsection{Trabalhos Relacionados}

Durante os últimos anos, diversas contribuições tecnológicas foram propostas com o intuito de apoiar o processo de avaliação de aprendizagem. As iniciativas surgiram a partir de diferentes segmentos, tais como acadêmico, privado e público, com soluções sob diferentes perspectivas. Dentre os trabalhos pesquisados, selecionou-se os que mais se aproximam do presente trabalho. No segmento acadêmico, destacam-se os trabalhos de Piva et al. (2017) e Bessa e Silva (2017). No segmento privado, destacamse as ferramentas Studos ${ }^{1}$ e AppProva ${ }^{2}$. Por fim, no segmento público, destaca-se a iniciativa do Governo do Paraná intitulada Prova Paraná ${ }^{3}$.

A iniciativa do setor acadêmico proposta em Piva et al. (2017) apresenta o SAA4 Sistema de Avaliação de Aprendizagem, uma ferramenta Web destinada a automatizar o processo de avaliação de aprendizagem, levando em consideração princípios da avaliação formativa e da metodologia de ensino de sala de aula invertida (também chamada de Flipped Classroom).

O trabalho apresentado por Bessa e Silva (2017) propõe o sistema Multiprova 5 destinado à elaboração e gerenciamento de avaliações. Além de criar as avaliações pelo sistema, o professor também pode corrigir as provas por um aplicativo associado à ferramenta. Este sistema também está disponível online e possui integração com o sistema de gestão acadêmica SIGAA. Para o desenvolvimento do Multiprova, também foram considerados elementos relacionados ao conceito de avaliação formativa.

No setor privado, a aplicação Studos propõe um sistema composto por módulos destinados aos pais, alunos, professores e gestores. O módulo destinado aos professores, permite a criação de provas e possui um banco de questões, tendo como foco principal otimizar o tempo do professor.

O AppProva é uma plataforma destinada aos alunos e as instituições de ensino, tendo como objetivo ajudar os professores a identificar os pontos falhos dos seus alunos e melhorar o processo de aprendizagem. Além disso, o sistema se propõe em otimizar o tempo dos professores, efetuar a comparação dos alunos com outros alunos de todo o Brasil e disponibiliza simulados que utilizam o mesmo critério de avaliação do Enem, a TRI (Teoria de Resposta ao Item).

Por fim, destaca-se uma interessante iniciativa da Secretaria de Educação do Governo do Paraná denominada Prova Paraná. O objetivo desta iniciativa é levantar informações sobre a qualidade do ensino no estado. A Prova Paraná caracteriza-se como uma

\footnotetext{
${ }^{1}$ Studos: <https://studos.com.br/>

${ }^{2}$ AppProva: <http://appprova.com.br/>

${ }^{3}$ Sistema Web da Prova Paraná: <https://provaparana.azurewebsites.net/>

${ }^{4}$ SSA: <http://www.saa.pro.br>

${ }^{5}$ Multiprova: <http://multiprova.ufrn.br/multiprova/>
} 
avaliação diagnóstica com o objetivo de contribuir na análise do nível de aprendizagem dos estudantes com relação às disciplinas de Língua Portuguesa e Matemática. Esta ferramenta é destinada a professores, gestores e secretários de educação, possibilitando que ações de melhoria de aprendizagem sejam tomadas com base nos diagnósticos obtidos. Nesta iniciativa, as avaliações são disponibilizadas na forma impressa às escolas da rede pública, um aplicativo é disponibilizado para correção e um sistema Web para que os usuários possam acompanhar os resultados das provas aplicadas.

\section{Metodologia}

A pesquisa foi conduzida de acordo com as etapas ilustradas na Figura 1. Na primeira etapa, foram buscadas escolas do setor público ou privado do município de Campo Mourão no estado do Paraná que estivessem reformulando seus currículos conforme a BNCC. Nessa etapa, estabeleceu-se uma parceria com uma escola do setor privado que possui o ciclo completo da educação básica. Em conjunto com a direção e coordenação pedagógica da escola, selecionou-se como objeto de investigação a avaliação da turma do $5^{\circ}$ ano do Ensino Fundamental I na disciplina de Matemática.

Após a definição do objeto de investigação, deu-se início à etapa de imersão que ocorreu no primeiro quadrimestre de 2019. Esta etapa consistiu em acompanhar o planejamento da avaliação da disciplina durante o quadrimestre. Foi obtida uma compreensão detalhada de como o professor planejava a avaliação diante da necessidade de verificar o desenvolvimento das habilidades requeridas pela BNCC. Observou-se como o professor articulou as habilidades norteadoras da BNCC com o seu planejamento de avaliação sob três perspectivas: (a) planejamento das aulas, (b) planejamento dos testes e (c) interpretação dos resultados dos testes. O entendimento resultante desta análise foi que, na perspectiva (a), o professor não mantinha um controle de quais habilidades eram estimuladas em cada aula. Ao final do primeiro quadrimestre, a partir do seu diário de classe, o professor não foi capaz de responder de forma precisa qual era a proporção em que as habilidades da BNCC foram estimuladas durante todo o período. Na perspectiva (b), o professor planejou testes para diagnosticar o progresso dos alunos com relação ao desenvolvimento das habilidades. No entanto, não se percebeu nenhum protocolo sistemático para a seleção das questões e atribuição dos pesos. Por fim, na perspectiva (c), o professor corrigiu os testes e atribuiu as notas. Para os alunos com nota inferior a 60, o professor oferecia uma atividade extra como oportunidade de recuperação. Tal como

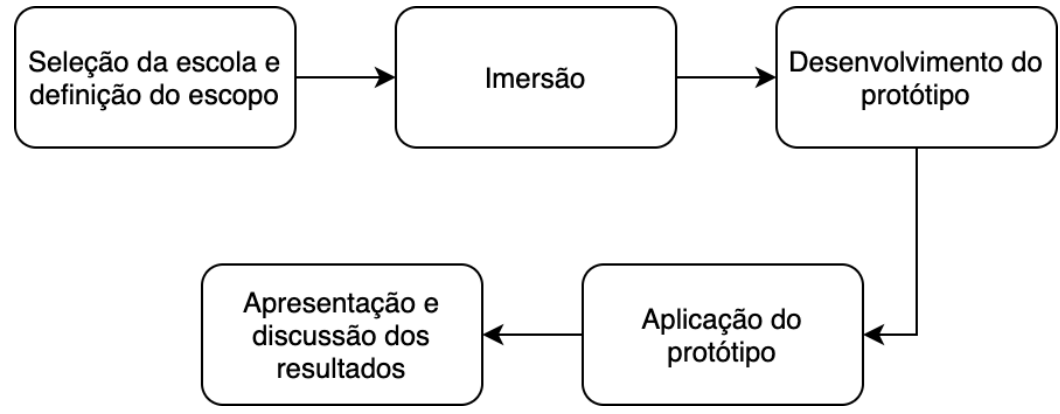

Figura 1 - Sequência das etapas desenvolvidas. 
nas outras perspectivas, não se teve nenhuma forma sistemática na interpretação dos resultados, pois o professor proporcionava formas de recuperação para os alunos, mas não tinha informações concretas de quais habilidades o aluno apresentou dificuldade.

A partir das dificuldades identificadas, teve início a etapa de desenvolvimento do protótipo sob as mesmas perspectivas da etapa anterior. Na perspectiva (a), foi desenvolvido um módulo para o professor registrar o seu diário de classe. Para cada aula, o professor registra o dia da aula, o conteúdo e a habilidade da BNCC estimulada pelo conteúdo ministrado. Na perspectiva (b), desenvolveu-se um módulo para auxiliar o professor no planejamento dos testes. Nesse módulo, o professor cria o teste e define para cada questão um peso e a habilidade que a questão objetiva avaliar. A Tabela 3 ilustra um exemplo do planejamento de um teste segundo o módulo desenvolvido.

\begin{tabular}{|c|c|c|c|}
\hline Questão & $\begin{array}{l}\text { Valor da } \\
\text { questão }\end{array}$ & $\begin{array}{l}\text { Código da } \\
\text { Habilidade }\end{array}$ & Descrição da Habilidade \\
\hline Q1 & 30 & EFo5MAo1 & $\begin{array}{l}\text { Ler, escrever e ordenar números naturais até a ordem } \\
\text { das centenas de milhar com compreensão das principais } \\
\text { características do sistema de numeração decimal. }\end{array}$ \\
\hline Q2 & 25 & EFo5MAO3 & $\begin{array}{l}\text { Identificar e representar frações (menores e maiores que a } \\
\text { unidade), associando-as ao resultado de uma divisão ou à } \\
\text { ideia de parte de um todo, utilizando a reta numérica como } \\
\text { recurso. }\end{array}$ \\
\hline Q4 & 10 & EFo5MAO4 & Identificar frações equivalentes. \\
\hline Q5 & 35 & EFO5MAO6 & $\begin{array}{l}\text { Associar as representações } 10 \%, 25 \%, 50 \%, 75 \% \text { e } 100 \% \\
\text { respectivamente à décima parte, quarta parte, metade, três } \\
\text { quartos e um inteiro, para calcular porcentagens, utilizando } \\
\text { estratégias pessoais, cálculo mental e calculadora, em } \\
\text { contextos de educação financeira, entre outros. }\end{array}$ \\
\hline Total & 100 & & \\
\hline
\end{tabular}

Tabela 3 - Exemplo do planejamento de um teste.

Na perspectiva (c), foi desenvolvido dois módulos: um para correção e outro para apresentação da síntese dos resultados. No módulo de correção, o professor registra a nota obtida por cada aluno em cada questão do teste planejado. A Tabela 4 ilustra um exemplo do módulo de resultados do teste exemplificado na Tabela 3. No módulo de síntese dos resultados, o professor tem acesso às informações sobre o resultado individual e da turma com base nas habilidades da BNCC. A Figura 2 ilustra uma tela do protótipo desenvolvido nesta etapa.

\begin{tabular}{llllll}
\hline Aluno & Nota final & $\begin{array}{l}\text { Q1 } \\
(\mathbf{3 0})\end{array}$ & $\begin{array}{l}\text { Q2 } \\
(\mathbf{2 5})\end{array}$ & $\begin{array}{l}\text { Q2 } \\
(\mathbf{1 0})\end{array}$ & $\begin{array}{l}\text { Q3 } \\
\mathbf{( 3 5 )}\end{array}$ \\
\hline Aluno1 & 65 & 25 & 20 & 0 & 25 \\
\hline Aluno2 & 91 & 28 & 23 & 10 & 30 \\
\hline Aluno3 & 55 & 20 & 15 & 5 & 15 \\
\hline Aluno4 & 85 & 30 & 10 & 10 & 35 \\
\hline
\end{tabular}

Tabela 4 - Exemplo do módulo de correção. 
Com o protótipo desenvolvido, a etapa de aplicação ocorreu no segundo quadrimestre de 2019. Nessa etapa, o professor apenas utilizou o protótipo para registrar as informações. O professor realizou o processo de avaliação da forma convencional sem o auxílio das informações produzidas pelo protótipo. Optou-se por essa estratégia para que, ao final do quadrimestre, o professor tivesse a oportunidade de refletir sobre as informações produzidas em comparação com sua abordagem tradicional. Esperavase que o professor ponderasse se as informações produzidas pelo protótipo teriam alterado seu planejamento da avaliação e sua interpretação dos resultados. Portanto, durante essa etapa o professor registrou no protótipo as aulas ministradas associando a elas as respectivas habilidades. Além disso, o professor também planejou e corrigiu três testes programados para o período utilizando o protótipo. Como mencionado, o professor fez a interpretação dos resultados da forma convencional sem o auxílio do protótipo.

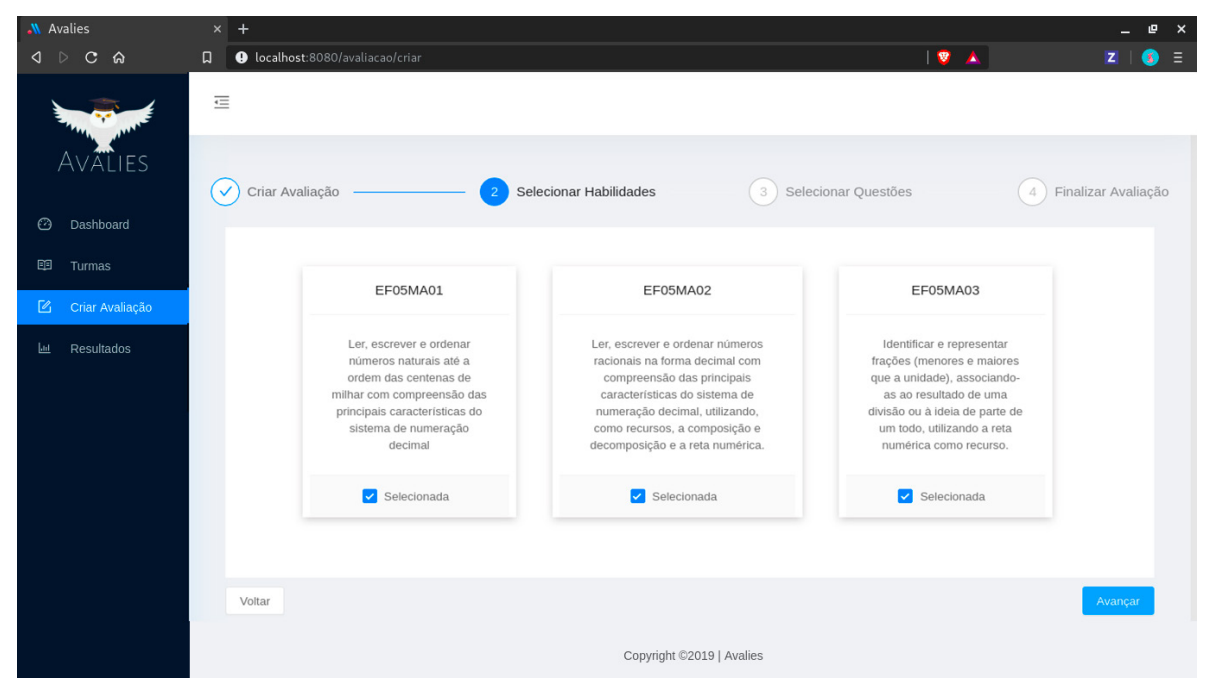

Figura 2 - Tela do planejamento do teste.

Finalizado o quadrimestre, teve início a última etapa do experimento apresentando as informações geradas pelo protótipo para o professor. Esta etapa foi realizada com a participação da coordenação pedagógica da escola e os resultados são apresentados no capítulo a seguir.

\section{Resultados e Discussões}

Os resultados são apresentados e discutidos sob as mesmas perspectivas utilizadas na metodologia. Esses resultados foram obtidos a partir da aplicação do protótipo na avaliação do segundo quadrimestre de 2019 da disciplina de matemática do $5^{\circ}$ ano do Ensino Fundamental I de uma escola do setor privado de Campo Mourão - PR. 


\subsection{Planejamento de aula}

Durante o período analisado, o professor registrou 42 aulas utilizando o protótipo. Como ilustra a Figura 3, o protótipo produziu o gráfico que mostra quais habilidades (e em que proporção) o professor trabalhou durante suas aulas. Em todo o quadrimestre, 13 das 25 habilidades foram alvo dos conteúdos das aulas ministradas. As habilidades mais estimuladas foram a EFo5MAo6 e a EFo5MAo8 com, aproximadamente, 20\% cada uma. As habilidades com menos aulas foram as EFo5MA10, EFo5MA16, EFo5MA21 e EFo5MA24 com uma única aula durante o período. O professor relatou que o gráfico trouxe informações que são difíceis de perceber no planejamento manual e que foi possível observar pontos passíveis de aperfeiçoamento.

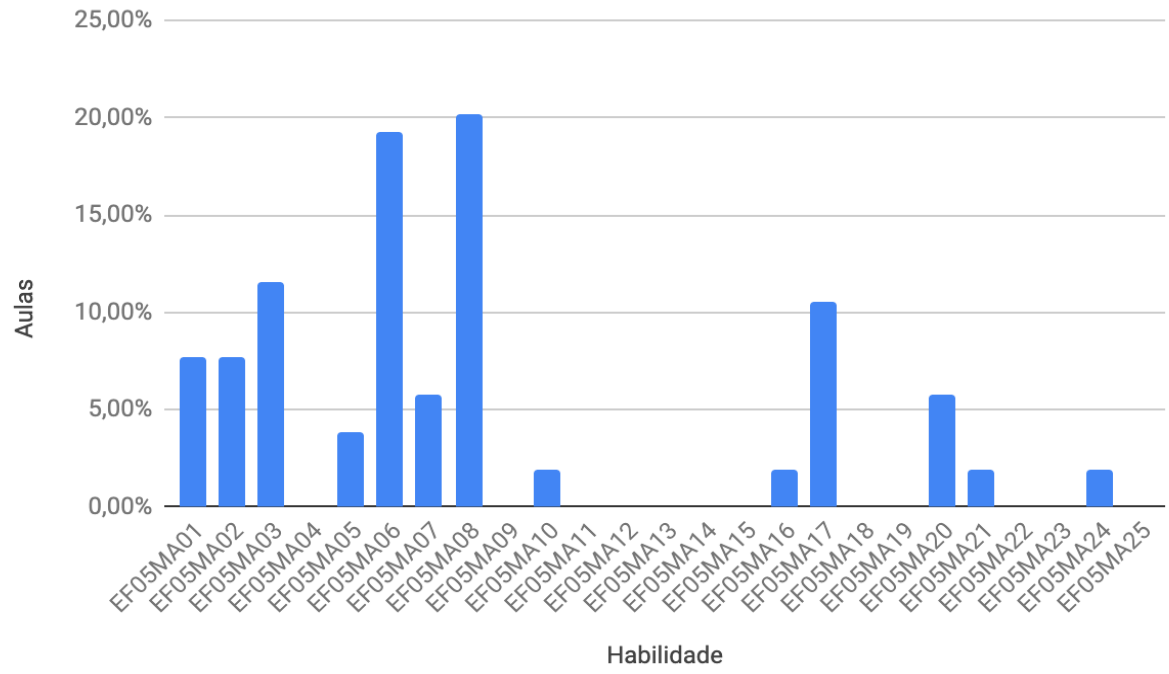

Figura 3 - Habilidades estimuladas durante as aulas.

\subsection{Planejamento da avaliação}

Durante o quadrimestre, o professor planejou três testes com o objetivo de avaliar o desenvolvimento dos alunos nas habilidades trabalhadas nas aulas. A Figura 4 apresenta o gráfico com o planejamento da avaliação com relação às habilidades, ou seja, qual o peso de cada habilidade no processo avaliativo. Essas informações foram produzidas com base no valor atribuído às questões e as respectivas habilidades. Ressalta-se que o esforço adicional despendido na elaboração das avaliações por meio do protótipo foi mínimo. $\mathrm{O}$ professor precisava inserir apenas três informações por questão: o identificador, o peso na avaliação e a habilidade avaliada. O professor avaliou 10 habilidades nos testes e as habilidades com mais peso na avaliação foram a EFo5MA01 e a EFo5MAo6 com, aproximadamente, $20 \%$. 
Algumas divergências foram identificadas entre o planejamento das aulas e o planejamento da avaliação. Para ilustrar essas divergências, a Figura 5 ilustra um gráfico com os planejamentos de aula e de avaliação no mesmo plano. Neste gráfico, percebe-se que a habilidade EFo5MAo8 recebeu mais atenção durante as aulas (20,19\%) e menos na avaliação (9,33\%). A habilidade EFo5MAO1 foi trabalhada em 7,69\% das aulas e mais do que o dobro na avaliação 20,50\%. A habilidade EFo5MAO4 não foi trabalhada em nenhuma aula, mas foi responsável por $8 \%$ da avaliação. Além disso, 4 habilidades foram trabalhadas em 11,54\% das aulas, mas não foram avaliadas nos testes.

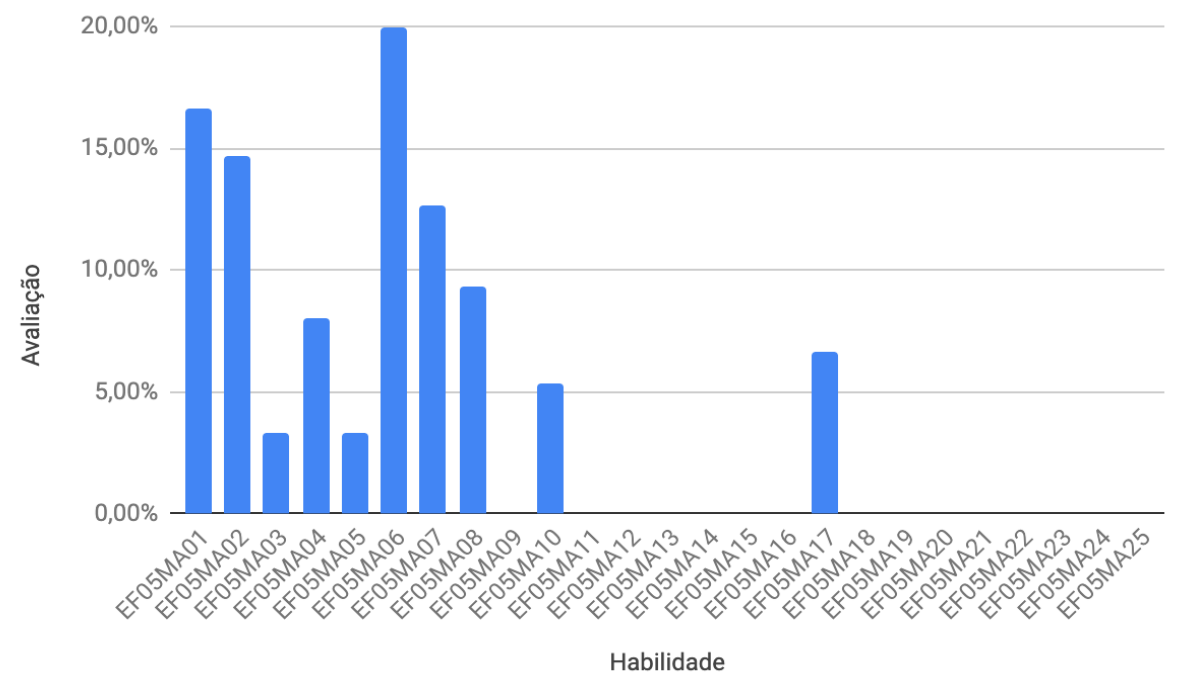

Figura 4 - Habilidades avaliadas pelos três testes.

As informações apresentadas na Figura 5 causaram surpresa no professor, pois a identificação de algumas divergências foi inesperada. O professor relatou que levará essas informações em consideração para o planejamento das aulas e da avaliação do terceiro quadrimestre.

Além disso, para cada teste, o protótipo também produziu um gráfico com a relevância das habilidades avaliadas. A Figura 6 ilustra a relevância das habilidades no primeiro teste planejado pelo professor. O gráfico demonstra que o professor planejou o teste para avaliar três principais habilidades: a EFo5MAo1 (26\%), a EFo5MAo6 (22\%) e a EFo5MA07 (28\%). A partir dessas informações, conclui-se que o desempenho das habilidades específicas tem maior relevância na avaliação. O professor relatou que, caso tivesse acesso a essas informações durante o planejamento do teste, elas teriam o auxiliado em uma melhor distribuição dos pesos nas questões. 


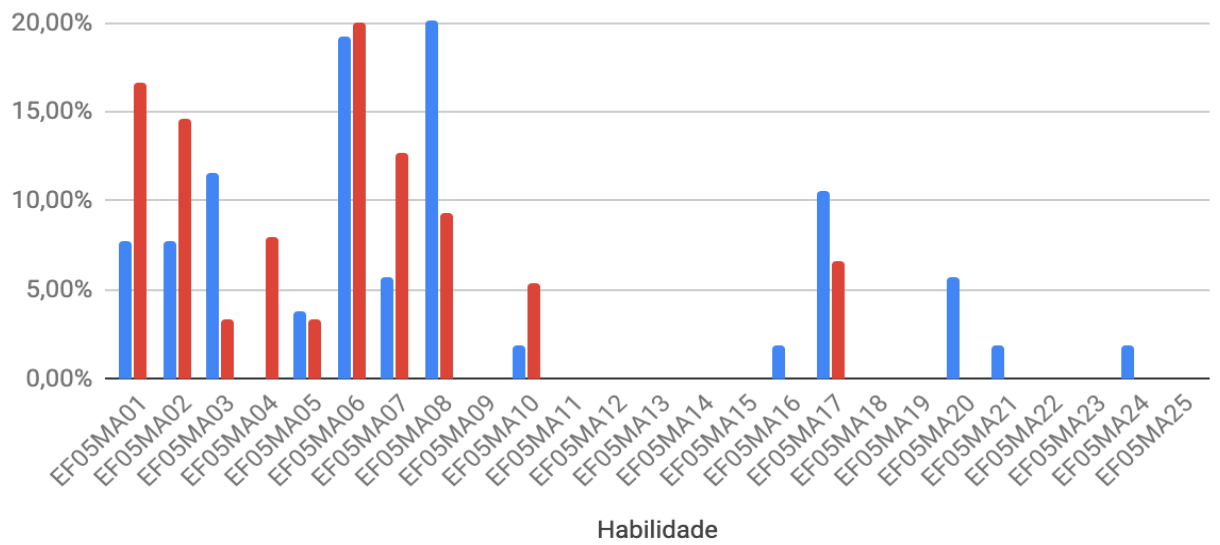

Figura 5 - Habilidades estimuladas durante as aulas e cobradas na avaliação.

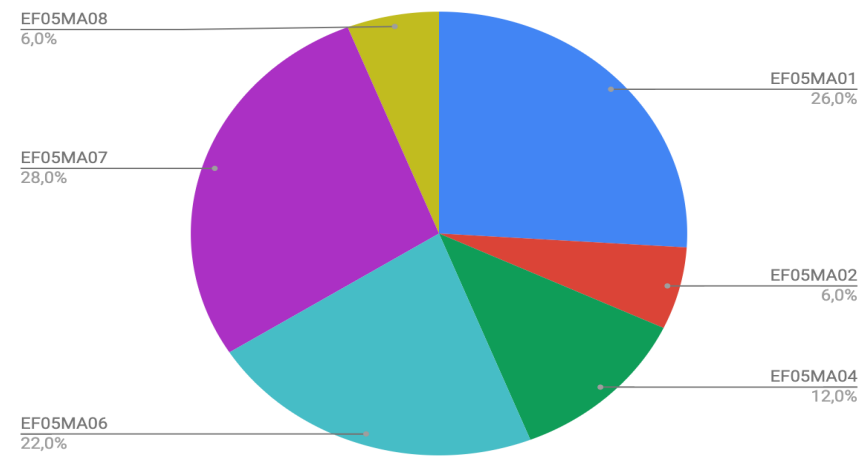

Figura 6 - Habilidades estimuladas durante as aulas e cobradas na avaliação.

\subsection{Interpretação dos resultados}

Após o registro das notas obtidas pelos alunos nos testes, o protótipo produziu informações individuais e da turma sobre o desempenho nas habilidades avaliadas. Em virtude do limite de páginas disponível, apresentamos os resultados dos três testes agrupados na Tabela 5. A tabela está ordenada em ordem decrescente pela média das notas obtidas pelos alunos nos três testes. 
A primeira coluna da tabela corresponde aos alunos cujos nomes foram preservados por privacidade. A segunda coluna apresenta a média das notas obtidas nos três testes e da terceira coluna em diante, os valores representam o desempenho do aluno na habilidade. Considerando somente a média das notas, é possível afirmar que o desempenho dos alunos foi bem satisfatório. A média da turma foi 75,79 e somente os alunos A25 e A11 não alcançaram a média escolar 60. No entanto, ao analisar o desempenho nas habilidades, alguns dados chamaram a atenção. O aluno A13 obteve a terceira maior média da turma, porém, não apresentou desempenho satisfatório em 3 das 10 habilidades avaliadas. Essa informação é relevante, pois a dificuldade demonstrada pelo aluno nas habilidades EFo5MA07, EFo5MAo8 e EFo5MA10 passa despercebida diante da média alta obtida por ele. Diversos outros alunos se encontram na mesma situação e a probabilidade de suas dificuldades passarem despercebidas pelo professor é expressiva. Outra informação que chamou a atenção foi o desempenho do aluno A14. Ele obteve apenas a oitava melhor média da turma $(79,33)$, mas apresentou desempenho satisfatório em todas as habilidades. Apenas três dos vinte e cinco alunos apresentaram desempenho satisfatório em todas as habilidades avaliadas.

O topo de cada coluna das habilidades representa a média do desempenho da turma na habilidade. Chama a atenção o baixo desempenho da turma nas habilidades EFo5MAo7 e EFo5MA10. Essa informação revela uma situação que merece uma investigação mais profunda para certificar o que ocorreu e planejar as intervenções pedagógicas, se necessário. O professor e a coordenação pedagógica se surpreenderam com os dados expostos por essa tabela. Eles relataram que a tabela traz à luz diversas informações que o professor não teria condições de perceber sem o auxílio da ferramenta. Também identificaram oportunidades de potencializar o aprendizado dos alunos. Uma das oportunidades discutidas foi o agrupamento dos alunos por dificuldades para a aplicação de uma recuperação direcionada à dificuldade específica.

\begin{tabular}{|c|c|c|c|c|c|c|c|c|c|c|c|}
\hline $\begin{array}{l}\text { Desemp } \\
\text { habilida }\end{array}$ & $\begin{array}{l}\text { enho por } \\
\text { ade }\end{array}$ & $68,34 \%$ & $80,83 \%$ & $71,43 \%$ & $\mathbf{8 1 , 7 4 \%}$ & $100,00 \%$ & $84,30 \%$ & $55,89 \%$ & $70,20 \%$ & $50,51 \%$ & $79,39 \%$ \\
\hline Alunos & $\begin{array}{c}\text { Média no } \\
\text { quadrimestre }\end{array}$ & $\begin{array}{c}\text { EFo5MA } \\
\text { o1 }\end{array}$ & $\begin{array}{c}\text { EFo5MA } \\
02\end{array}$ & $\begin{array}{c}\text { EFo5MA } \\
03\end{array}$ & $\begin{array}{c}\text { EFo5MA } \\
04\end{array}$ & $\begin{array}{l}\text { EFO5MA } \\
\quad 05\end{array}$ & $\begin{array}{c}\text { EFo5MA } \\
\text { o6 }\end{array}$ & $\begin{array}{c}\text { EFo5MA } \\
\text { o7 }\end{array}$ & $\begin{array}{c}\text { EFo5MA } \\
\text { o8 }\end{array}$ & $\begin{array}{c}\text { EFo5MA } \\
10\end{array}$ & $\begin{array}{c}\text { EFo5MA } \\
17\end{array}$ \\
\hline A15 & 96,00 & $79,40 \%$ & $100,00 \%$ & $100,00 \%$ & $100,00 \%$ & $100,00 \%$ & $100,00 \%$ & $97,22 \%$ & $100,00 \%$ & $100,00 \%$ & $80,00 \%$ \\
\hline Ao5 & 92,67 & $90,48 \%$ & $86,90 \%$ & $100,00 \%$ & $91,67 \%$ & $100,00 \%$ & $100,00 \%$ & $100,00 \%$ & $100,00 \%$ & $75,00 \%$ & $66,31 \%$ \\
\hline $\mathrm{A} 13$ & $\mathbf{8 8 , 6 7}$ & $98,61 \%$ & $97,22 \%$ & $100,00 \%$ & $91,67 \%$ & $100,00 \%$ & $100,00 \%$ & $53,89 \%$ & $50,00 \%$ & $50,00 \%$ & $80,00 \%$ \\
\hline $\mathrm{A} 18$ & 88,67 & $81,48 \%$ & $100,00 \%$ & $100,00 \%$ & $83,34 \%$ & $100,00 \%$ & $100,00 \%$ & $58,34 \%$ & $91,67 \%$ & $62,50 \%$ & $80,00 \%$ \\
\hline A19 & 86,67 & $59,72 \%$ & $86,90 \%$ & $100,00 \%$ & $91,67 \%$ & $100,00 \%$ & $100,00 \%$ & $63,89 \%$ & $100,00 \%$ & $75,00 \%$ & $70,48 \%$ \\
\hline A24 & 86,33 & $62,50 \%$ & $78,40 \%$ & $100,00 \%$ & $91,67 \%$ & $100,00 \%$ & $100,00 \%$ & $47,22 \%$ & $100,00 \%$ & $100,00 \%$ & $80,00 \%$ \\
\hline Ao2 & 86,00 & $90,48 \%$ & $97,92 \%$ & $100,00 \%$ & $79,17 \%$ & $100,00 \%$ & $100,00 \%$ & $62,04 \%$ & $75,00 \%$ & $37,50 \%$ & $100,00 \%$ \\
\hline A14 & 79,33 & $66,20 \%$ & $74,01 \%$ & $100,00 \%$ & $91,67 \%$ & $100,00 \%$ & $97,92 \%$ & $66,67 \%$ & $66,67 \%$ & $75,00 \%$ & $75,24 \%$ \\
\hline $\mathrm{Ao} 4$ & 78,67 & $87,70 \%$ & $90,05 \%$ & $100,00 \%$ & $75,00 \%$ & $100,00 \%$ & $66,67 \%$ & $65,00 \%$ & $75,00 \%$ & $50,00 \%$ & $80,00 \%$ \\
\hline
\end{tabular}




\begin{tabular}{|c|c|c|c|c|c|c|c|c|c|c|c|}
\hline \multicolumn{2}{|c|}{$\begin{array}{l}\text { Desempenho por } \\
\text { habilidade }\end{array}$} & \multirow{2}{*}{$\begin{array}{c}68,34 \% \\
\text { EFo5MA } \\
\text { o1 }\end{array}$} & \multirow{2}{*}{$\begin{array}{c}80,83 \% \\
\text { EFO5MA } \\
02\end{array}$} & \multirow{2}{*}{$\begin{array}{c}71,43 \% \\
\text { EFo5MA } \\
03\end{array}$} & \multirow{2}{*}{$\begin{array}{c}81,74 \% \\
\text { EFo5MA } \\
04\end{array}$} & \multirow{2}{*}{$\begin{array}{c}100,00 \% \\
\text { EFo5MA } \\
\text { o5 }\end{array}$} & \multirow{2}{*}{$\begin{array}{c}84,30 \% \\
\text { EFo5MA } \\
06\end{array}$} & \multirow{2}{*}{$\begin{array}{c}55,89 \% \\
\text { EFo5MA } \\
\text { o7 }^{2}\end{array}$} & \multirow{2}{*}{$\begin{array}{c}70,20 \% \\
\text { EFo5MA } \\
\text { o8 }\end{array}$} & \multirow{2}{*}{$\begin{array}{c}50,51 \% \\
\text { EFo5MA } \\
10\end{array}$} & \multirow{2}{*}{$\begin{array}{c}79,39 \% \\
\text { EFo5MA } \\
17\end{array}$} \\
\hline Alunos & $\begin{array}{c}\text { Média no } \\
\text { quadrimestre }\end{array}$ & & & & & & & & & & \\
\hline A22 & 78,33 & $60,42 \%$ & $79,94 \%$ & $100,00 \%$ & $83,34 \%$ & $100,00 \%$ & $94,44 \%$ & $58,34 \%$ & $57,15 \%$ & $37,50 \%$ & $80,00 \%$ \\
\hline A12 & 77,33 & $97,62 \%$ & $80,88 \%$ & $0,00 \%$ & $100,00 \%$ & $100,00 \%$ & $75,00 \%$ & $48,34 \%$ & $75,00 \%$ & $37,50 \%$ & $75,24 \%$ \\
\hline A2O & 76,67 & $67,26 \%$ & $83,73 \%$ & $100,00 \%$ & $75,00 \%$ & $100,00 \%$ & $83,33 \%$ & $72,22 \%$ & $91,67 \%$ & $25,00 \%$ & $95,24 \%$ \\
\hline Ao9 & 76,00 & $66,40 \%$ & $93,75 \%$ & $0,00 \%$ & $100,00 \%$ & $100,00 \%$ & $83,33 \%$ & $51,11 \%$ & $66,67 \%$ & $25,00 \%$ & $80,00 \%$ \\
\hline Ao3 & 75,67 & $68,09 \%$ & $75,32 \%$ & $100,00 \%$ & $91,67 \%$ & $100,00 \%$ & $100,00 \%$ & $61,11 \%$ & $41,67 \%$ & $25,00 \%$ & $95,24 \%$ \\
\hline $\mathrm{Ao} 7$ & 74,67 & $52,58 \%$ & $67,28 \%$ & $100,00 \%$ & $100,00 \%$ & $100,00 \%$ & $83,33 \%$ & $30,56 \%$ & $75,00 \%$ & $50,00 \%$ & $80,00 \%$ \\
\hline Ao8 & 72,67 & $88,89 \%$ & $84,67 \%$ & $0,00 \%$ & $75,00 \%$ & $100,00 \%$ & $77,78 \%$ & $52,78 \%$ & $75,00 \%$ & $62,50 \%$ & $66,31 \%$ \\
\hline $\mathrm{A} 21$ & 72,00 & $50,13 \%$ & $96,06 \%$ & $100,00 \%$ & $58,34 \%$ & $100,00 \%$ & $77,78 \%$ & $69,45 \%$ & $66,67 \%$ & $100,00 \%$ & $80,00 \%$ \\
\hline A16 & 70,00 & $55,69 \%$ & $80,95 \%$ & $0,00 \%$ & $83,34 \%$ & $100,00 \%$ & $83,33 \%$ & $36,11 \%$ & $75,00 \%$ & $50,00 \%$ & $57,74 \%$ \\
\hline A23 & 69,00 & $44,84 \%$ & $86,11 \%$ & $100,00 \%$ & $75,00 \%$ & $100,00 \%$ & $66,67 \%$ & $42,78 \%$ & $78,81 \%$ & $50,00 \%$ & $80,00 \%$ \\
\hline A01 & 68,67 & $28,57 \%$ & $59,04 \%$ & $100,00 \%$ & $91,67 \%$ & $100,00 \%$ & $88,19 \%$ & $50,19 \%$ & $66,67 \%$ & $25,00 \%$ & $61,90 \%$ \\
\hline Ao6 & 68,00 & $56,98 \%$ & $74,09 \%$ & $100,00 \%$ & $50,00 \%$ & $100,00 \%$ & $83,33 \%$ & $61,11 \%$ & $66,67 \%$ & $25,00 \%$ & $95,24 \%$ \\
\hline A10 & 65,33 & $83,04 \%$ & $74,31 \%$ & $0,00 \%$ & $83,34 \%$ & $100,00 \%$ & $77,78 \%$ & $40,00 \%$ & $41,67 \%$ & $12,50 \%$ & $80,00 \%$ \\
\hline A17 & 60,33 & $56,91 \%$ & $75,00 \%$ & $0,00 \%$ & $62,50 \%$ & $100,00 \%$ & $72,22 \%$ & $33,34 \%$ & $50,00 \%$ & $37,50 \%$ & $100,00 \%$ \\
\hline A25 & 57,67 & $67,16 \%$ & $42,06 \%$ & $100,00 \%$ & $58,34 \%$ & $100,00 \%$ & $50,00 \%$ & $40,00 \%$ & $25,00 \%$ & $37,50 \%$ & $75,24 \%$ \\
\hline A11 & 44,00 & $17,46 \%$ & $39,90 \%$ & $0,00 \%$ & $66,67 \%$ & $100,00 \%$ & $49,31 \%$ & $31,67 \%$ & $41,67 \%$ & $25,00 \%$ & $61,90 \%$ \\
\hline
\end{tabular}

Tabela 5 - Resultado da avaliação do quadrimestre

\section{Conclusão}

Este trabalho propõe a investigação do impacto que uma ferramenta tecnológica pode proporcionar aos professores na elaboração e interpretação da avaliação das habilidades propostas pela Base Nacional Comum Curricular. A hipótese é que o apoio tecnológico produza informações significativas que potencialize a eficácia da avaliação no processo de ensino-aprendizagem. A investigação foi conduzida pelas seguintes Questões de Pesquisa: (QP1) A ferramenta tecnológica evidenciou informações que foram imperceptíveis ao professor na avaliação dos alunos segundo as habilidades propostas na BNCC? (QP2) As informações evidenciadas pela ferramenta tecnológica proporcionaram reflexões sobre possíveis intervenções pedagógicas?

Em resposta à QP1, os resultados mostraram que a ferramenta foi capaz de revelar diversas informações não percebidas pelo professor, tanto no âmbito do planejamento da avaliação quanto da interpretação dos resultados. No planejamento da avaliação, foi possível identificar, por exemplo, algumas habilidades que foram avaliadas de forma desproporcional ao estímulo recebido durante as aulas. Na interpretação dos resultados, 
o bom desempenho da turma nos testes aplicados encobriu algumas informações relevantes. Embora somente dois alunos não tenham alcançado a média determinada pela escola (60), o protótipo revelou que 23 dos 25 alunos apresentam dificuldades em alguma habilidade avaliada. Em uma situação particular, um aluno cuja média foi 88,67 , apresentou dificuldades em 3 das 10 habilidades avaliadas. Outra informação que merece destaque foi a dificuldade expressiva que a turma apresentou nas habilidades EFo5MA07 e EFo5MA10.

Com relação à QP2, a discussão dos resultados com o professor e a coordenação pedagógica revelou oportunidades de replanejamento e intervenções pedagógicas. Por exemplo, com as informações apresentadas na Tabela 5, o professor pode promover estudos individualizados com base na dificuldade específica do aluno.

Na sequência, será dado um acompanhamento da turma investigada e uma ampliação na utilização do protótipo com outras disciplinas para o amadurecimento e aprimoramento da ferramenta.

\section{Referências}

Bessa, A., \& Silva, D. (2017). Multiprova: Aprimorando a Avaliação com o Uso da Tecnologia. Revista Renote, (15), 1-10. doi:10.22456/1679-1916.75123

Carneiro, V. F., Pequeno, A. M. C., Machado, M. A. S., Aguiar, D. M. L, Carneiro, C., \& Carneiro, R. F. (2017). Avaliação da Aprendizagem: Concepções e Olhares de Docentes do Curso de Odontologia. Revista Ibero-Americana De Estudos Em Educação, (12), 900-915. doi: 10.21723/riaee.v12.n2.8486

Duran, D. F., Chanchí, G. E., \& Arciniegas, J. L. (2017). Evaluación de mapas de competencias educativas: una propuesta difusa basada en 2-tuplas. RISTI - Revista Ibérica de Sistemas e Tecnologias de Informação, (24), 22-38. doi: 10.17013/ risti.24.22-38

Freitas, S., da Costa, M., \& de Miranda, F. (2014). Avaliação Educacional: formas de uso na prática pedagógica. Revista Meta: Avaliação, 85-98. doi: 10.22347/21752753v6i16.217

Heinsfeld, B., \& da Silva, M. (2018). As Versões da Base Nacional Comum Curricular (BNCC) e o Papel das Tecnologias Digitais: Conhecimento da Técnica versus Compreensão dos Sentidos. Currículo Sem Fronteiras, (18), 668-690.

Luckesi, C. C. (2005). Avaliação da aprendizagem escolar (17 ${ }^{\mathrm{a}}$ ed.). São Paulo: Cortez Editora.

Ministério da Educação (2018). Base Nacional Comum Curricular. Brasília: Fundação Carlos Alberto Vanzolin.

Nascimento, A. S. (2017). Avaliação da Aprendizagem nos Ciclos de Formação Humana. Revista Eventos Pedagógicos, (22), 645-665. 
Piva, D., Cortelazzo, A., Freitas, F., \& Belo, R. (2017). Sistema de Avaliação da Aprendizagem (SAA): Operacionalização da Metodologia Flipped Classroom. Congresso Internacional Da ABED De Educação A Distância. doi: 10.17143/ciaed/ XXIICIAED.2016.00262

Senado Federal (2018). Lei de Diretrizes e Bases da Educação Nacional. Brasília: Coordenação de Edições Técnicas.

Torres, N. B., González, R. L., \& Carvalho, J. L. (2018). Roamer, un robot en el aula de Educación Infantil para el desarrollo de nociones espaciales básicas. RISTI - Revista Ibérica de Sistemas e Tecnologias de Informação, (28), 14-28. doi: 10.17013/ risti.28.14-28 